\title{
Blood-Brain Barrier Degradation and the Implication of SPARC Protein as a Potential Therapeutic Target for Alzheimer's Disease
}

\author{
Alexander Pilozzi ${ }^{1}$ - Caitlin Carro ${ }^{1} \bullet$ Michael Whalen $^{2} \bullet$ Xudong Huang $^{1}$ \\ ${ }^{1}$ Neurochemistry Laboratory, Department of Psychiatry, Massachusetts General Hospital and \\ Harvard Medical School, Charlestown, MA, USA; ${ }^{2}$ Neuroscience Center, Department of \\ Pediatrics, Massachusetts General Hospital and Harvard Medical School, Boston, MA, USA
}

Author for correspondence: Xudong Huang, Neurochemistry Laboratory, Department of Psychiatry, Massachusetts General Hospital and Harvard Medical School, Charlestown, MA, USA. Email: Huang.Xudong@mgh.harvard.edu

Doi: https://doi.org/10.36255/exonpublications.alzheimersdisease.2020.ch8

\begin{abstract}
Alzheimer's disease is a progressive neurodegenerative disorder affecting a substantial portion of the older population, with the number of afflicted individuals expected to grow with time. Although numerous contributing factors to the disorder have been identified, there is currently no cure or effective prevention method. With the situation as dire as it is, many efforts have been made to shed light on the mechanisms tying diverse contributing factors to the pathogenesis of Alzheimer's disease. One common neuropathological feature of Alzheimer's disease is the dysfunction of the blood-brain barrier, which normally maintains brain homeostasis by isolating it from the peripheral circulation and mediating the transport of various bloodborne elements in and out of the brain. An increase in the blood-brain barrier permeability has been observed in Alzheimer's disease at a level considerably above normal aging. This chapter provides an overview of the effects of aging, the neuroimmune system, inflammation, traumatic brain injury, apolipoprotein E gene $\varepsilon 4$ allele, and secreted protein acidic and rich in cysteine (SPARC) protein on blood-brain barrier. The potential
\end{abstract}

In: Alzheimer's Disease: Drug Discovery. Huang X (Editor). Exon Publications, Brisbane, Australia. ISBN: 978-0-6450017-0-9; Doi: https://doi.org/10.36255/exonpublications.alzheimersdisease.2020 Copyright: The Authors.

License: This open access article is licenced under Creative Commons Attribution-NonCommercial 4.0 International (CC BY-NC 4.0) https://creativecommons.org/licenses/by-nc/4.0/ 
of SPARC as a therapeutic target for Alzheimer's disease, and the application of deep-learning-based virtual screening tools against SPARC protein are explored.

Keywords: Alzheimer's disease; blood-brain barrier; Hevin; secreted protein acidic and rich in cysteine; virtual screening

\section{INTRODUCTION}

Alzheimer's disease (AD) is a progressive neurodegenerative disorder that has widespread detrimental effects on memory and cognitive abilities that worsen over time. The disease is ultimately fatal, often through complications associated with decreased cognition. It is the most common form of senile dementia, with an estimated 5.8 million Americans currently afflicted with AD, a number that is expected to increase dramatically with an aging population that is more consistently reaching the "oldest-old" phase where AD risk is at its highest (1). AD has a substantial economic impact, with projections indicating the global cost of dementia could balloon to 2 trillion US dollars by 2030 (2). Given the threat the disease poses, researchers have been tackling AD from different angles, but as of now attempts to develop treatments have been met with widespread clinical failure (3).

The blood-brain barrier (BBB) consists of endothelial cells, serving as a layer of separation between blood vessels and the brain. The endothelia that line the blood vessels of the brain serve to isolate the brain parenchyma from bloodborne molecules that lack corresponding transporters to mediate their entry, and maintain the equilibrium of the brain's environment. The barrier is also comprised of other elements interacting with endothelial cells, including astrocyte foot processes and pericytes, which together with neurons and microglia comprise the neurovascular unit. The BBB is also responsible for controlling immune surveillance within the brain, by restricting the flow of immune cells (4). Dysfunction of the BBB is implicated in AD pathogenesis. The $\mathrm{BBB}$ is partially responsible for the clearance of amyloid-beta $(A \beta)$, which builds up and forms plaques in $\mathrm{AD}$, and the $\mathrm{BBB}$ is a site of $\mathrm{CNS}$ inflammation, which is frequently observed in $\mathrm{AD}$ patients (5).

While the integrity of the BBB is tightly regulated, emerging evidence implicates the matricellular proteins, secreted protein acidic and rich in cysteine (SPARC), and Hevin, as having a role in regulating BBB permeability. This chapter discusses the effects of various AD risk factors on BBB permeability, with emphasis on SPARC, which is upregulated in AD brain tissue $(6,7)$. Since the SPARC protein enhances BBB permeability, promotes neuroinflammation, and prolongs pro-inflammatory Ml phase of microglia, its potential as a druggable target is also discussed.

\section{THE BBB IN AD}

The integrity of the BBB is critical to the maintenance of brain homeostasis in health. As mentioned, BBB dysfunction is commonly seen in cases of AD, and a variety of factors may contribute to the observed disruption. 


\section{Aging}

Age is perhaps the most predominant risk factor for $\mathrm{AD}$, with almost half of all individuals over the age of 85 suffering from it; conversely, less than 10\% of cases under the age of 65 suffer from AD (8). BBB deterioration has been welldocumented in aging (9), with nearly all its components being affected (Table 1). Degradation of the BBB is known to start early, with notable permeability increases around the hippocampal region in individuals between 23 and 47 years of age, which worsens with increasing age $(9,10)$. Hormones such as insulin, which are associated with aging, can affect the permeability of the BBB and contribute to leakage (11). Additionally, transporters of certain molecules such as glucose, along with various proteins and hormones, may become defective in older individuals, reducing their availability to the brain (12). Outside of the barrier, the appearance of white matter hyperintensities, which are indicative of a loss of vascular integrity, also correlates with age. Damaged vasculature may cause a corresponding decrease in BBB integrity (13). Corroborating this, the vascular density of the brain appears to experience a significant age-related decline between the ages of 57 and 90 (14). Hypertension, which is more common in older individuals, can contribute to microvascular injury, thereby increasing the incidence of BBB disruption $(15,16)$.

\section{TABLE 1 Alterations of BBB components during physiological aging}

\begin{tabular}{ll}
\hline BBB element & Property changes due to aging \\
\hline Endothelial cells & Increased capillary wall thickness \\
& Decreased number of endothelial cells \\
Tight junctions & Decreased number of mitochondria \\
Basal lamina & Decreased expression of tight junction protein \\
& Increased thickness of basement membrane \\
& Increased concentration of collagen IV and arginase \\
Astrocytes & Decreased concentration of laminin \\
& Increased astrocyte proliferation \\
Microglia & Increased GFAP expression \\
& Changes to amoeboid morphology \\
Pericytes & Production of neurotoxic proinflammatory mediators \\
& Degeneration and loss of pericytes \\
& Vesicular and lipofuscin-like inclusions \\
Increased size of mitochondria \\
Fourony transformation \\
Deterioration of synaptic plasticity \\
Deficit in long-term potentiation \\
Impaired neurogenesis \\
Increased apoptosis \\
Neuronal damage due to cytokine release
\end{tabular}

Adapted from (9). GFAP, glial fibrillary acidic protein; BBB, blood-brain barrier. 


\section{Neuroimmunity}

The brain exists in a state that is considered "immune privileged." Due to the existence of barriers between the brain and the rest of the body's circulation, the brain is insulated against many peripheral immune events (17). The presence of immune cells derived from main circulation, such as peripheral macrophages, neutrophils, and leukocytes, in the brain is an indication of BBB breakdown (18). In addition, the brain has intrinsic immune components, and these components interact with the BBB in such a way that peripheral immune events can also invoke a response in the brain (17). There are two primary types of neuroimmune cells, microglia and astrocytes, and both interact with the BBB.

Microglia are a variant of macrophage, though they do not develop and function as peripheral macrophages do. Microglial progenitors emerge from the yolk sac, and the development of microglia occurs in phases, with each phase being regulated by different transcription factors, and exhibiting differing gene expression profiles (19). Some of their key functions include phagocytosis, synapse pruning, and mediating immune signaling through the release of cytokines and other factors (20). They play a role in AD primarily by phagocytizing abnormal $A \beta$ amyloid and forming a barrier between the plaques and the rest of the brain through plaque envelopment, thereby limiting the expansion of the plaque (21). Microglia are known to associate tightly with the BBB. Microglia exist in a resting state until they are activated due to brain injury or another immunological stimulus. Upon activation, they release a host of cytokines and other molecules that increase the permeability of the BBB; in the case of brain injury, this allows bloodborne agents like myeloid cells to cross the BBB. They also have been found to release reactive oxygen species that impair the function of the BBB (22). Perhaps, the most significant contribution of microglia to AD pathology is their involvement in evoking inflammatory responses within the brain (23). The role of inflammation in BBB disruption is discussed further in the following section.

Astrocytes are of epithelial origin and feature a wide array of morphologies and functions within the nervous system. Aside from their roles in neural immunity, they are responsible for ion transport, removal and catabolism of neurotransmitters, and neurogenesis. Some astrocytes are noted for their vascular end-feet, which are closely associated with brain vasculature and the BBB (24). They increase the permeability of the BBB through vascular endothelial growth factor A (VEGFA) and thymidine phosphorylase (TYMP). VEGFA, along with the TYMP product 2-deoxy-d-ribose, downregulates tight-junction proteins and promotes angiogenesis and BBB permeability (25). The release of these two factors is induced by interleukin-1 beta (IL-1 $\beta$ ), an inflammatory cytokine (25). Both astrocytes and microglia produce and react to inflammatory responses that can impact BBB health primarily through inflammatory cytokines (26).

\section{Neuroinflammation}

Neuroinflammation has been found to be relevant to AD pathology in a variety of ways. Inflammation in the brain has widespread effects on vasculature, cell signaling, neural function, and other immune responses. The effect of cytokines and other inflammatory mediators released during an inflammatory event involve some of the key components of the neuroimmune system and have been found to regulate the 
clearance of $A \beta$ (27). Many of these mediators have also been shown to influence BBB permeability. A summary of some of the mediators and their effects on the BBB are given in Table 2 (28). Neuroinflammation is a common effect of aging and notably includes an increase in the production of inflammatory cytokines by microglial cells (29). These mediators, in general, are not directly responsible for modulating the permeability of the BBB. Instead, they influence the expression or activation of other factors that, in turn, disrupt the BBB function (30).

\section{Traumatic brain injury}

Traumatic brain injury (TBI) has been shown to be a significant risk factor for AD. Individuals who had experienced a mild traumatic brain injury (mTBI) are more vulnerable to early-onset cognitive impairment (31) than those that have not experienced such an event. The effects of a TBI are often immediate, with force-induced injury resulting in what is considered secondary brain damage, which includes an increase in BBB permeability. Following TBI and mTBI, bloodborne substances accumulate in various regions of the brain, due to a breach in the BBB. While, in most cases, the effects of mTBI appear to be relatively short-lived, in rats with preexisting hypertension, mTBI can induce persistent disruption of the BBB (32). These rats experienced an increase in fibrin accumulation and neuronal expression of inflammatory cytokines (32). Generally, a focal breach following mTBI has been observed in rats to persist for

\section{IABLE 2 Inflammatory mediators and their effect upon the BBB}

\begin{tabular}{|c|c|}
\hline $\begin{array}{l}\text { Inflammatory } \\
\text { mediator }\end{array}$ & Observed effects on BBB \\
\hline \multirow[t]{4}{*}{$\mathrm{TNF}-\alpha$} & Increase in $\mathrm{BBB}$ permeability in in vivo and in vitro models \\
\hline & Increased efflux of albumin from brain to blood \\
\hline & Decreased ZO-1 expression \\
\hline & Increased MMP-9 protein expression \\
\hline \multirow[t]{4}{*}{ IL-1 $\beta$} & Increase in $\mathrm{BBB}$ permeability in in vivo and in vitro models \\
\hline & $\begin{array}{l}\text { Decreased TEER of primary cultures of brain endothelial cells and human } \\
\text { brain endothelial cells }\end{array}$ \\
\hline & Increased production of PGE and COX \\
\hline & Decreased ZO-1 expression \\
\hline \multirow[t]{2}{*}{ IL-6 } & $\begin{array}{l}\text { Decreased TEER in cerebrovascular endothelial cells from rats at higher doses } \\
\text { but not at lower doses }\end{array}$ \\
\hline & Decreased BBB permeability in ischemic brain in rodents \\
\hline IL-17A & Increase in BBB permeability in in vivo and in vitro models \\
\hline \multirow[t]{2}{*}{ CRP } & Increase in BBB permeability in in vivo and in vitro models \\
\hline & Increase in ROS production in brain endothelial cells \\
\hline
\end{tabular}

Adapted from (28). BBB, blood brain barrier; COX, cyclooxygenase; CRP, c-reactive protein; IL, interleukin; MMP-9, matrix metalloproteinase-9; PGE, prostaglandin E; ROS, reactive oxygen species; TEER, transepithelial/transendothelial electrical resistance; TNF- $\alpha$, tumor necrosis factor alpha; ZO-1, zonula occludens- 1 
approximately 24-48 h $(33,34)$. In rare occurrences, singular instances of BBB disruption via mTBI in humans, typically measured by the cerebrospinal fluid/ serum albumin quotient, have been found to persist for months or even years (35). A meta-analysis of studies conducted from 1995 to 2012 found that TBI and mTBI events are substantial risk factors for AD (36). The BBB disruption at the onset of TBI is relatively short-lived; however, the subsequent events lead to structural degeneration in the brain causing long-lasting cognitive impairments (37). Disruption of the BBB has been observed to be a marker of mild cognitive impairment independently of the neurofibrillary tangles (NFTs), tau protein, and $A \beta$ amyloid plaques, indicating that substantial breakdown of the $B B B$ itself contributes to cognitive decline in addition to exacerbating other neurodegenerative processes in AD (38).

\section{Apolipoprotein E gene $\varepsilon 4$ allele (APOE $\varepsilon 4)$}

The APOE $\varepsilon 4$ allele has been identified as the most significant genetic risk factor for AD (39). It is also associated with other dementia subtypes, such as Parkinson's (40) and frontotemporal dementias $(41,42)$. Individuals homozygous for APOE4 $(\varepsilon 4 / \varepsilon 4)$ experience a 10 -fold higher risk of dementia, and individuals heterozygous $(\varepsilon 3 / \varepsilon 4)$ for the variant experience a 1.7 -fold higher risk of dementia (43). APOE4 is attributed to reduced clearance of $A \beta$ amyloid, which contributes to the formation of the A $\beta$ amyloid plaques that are a hallmark of AD (44). Possession of at least one APOE4 allele increases the leakage of the $\operatorname{BBB}(45,46)$. The role of $\mathrm{APOE}$ in maintaining the integrity of the $\mathrm{BBB}$ is confirmed by experiments involving $\mathrm{APOE}$ deficient $\left(\mathrm{APOE}^{-/-}\right)$mice, which exhibit signs of increased $\mathrm{BBB}$ permeability, such as the leakage of exogenous tracers, starting at 2 weeks old (18). The allele may also have relevance to TBI. When assessing the BBB repair ability of APOE3 and APOE4 mice, the APOE3 mice experienced a significant reduction in permeability between the 3-day and 10-day measurements, indicating substantial BBB repair. APOE4 mice, however, did not experience a significant reduction in permeability in the same time period; APOE4 was also expressed at lower levels than APOE3 at both 3 and 10 days (47). The role of APOE in BBB integrity is further reinforced by postmortem studies of both AD and normal humans with and without the APOE4 allele. AD-afflicted APOE4 carriers experienced a 3.1-fold increase in fibrin perivascular deposits in the brain relative to APOE3 carriers, indicating an increase in BBB permeability. The same study also found that APOE3 carriers still had a 6.9-fold increase in A $\beta$ amyloid deposits relative to normal controls, indicating that $\mathrm{BBB}$ disruption is indeed a significant component of AD. In addition, pericytes, which are constituents of the BBB, have substantially reduced coverage in both AD and normal individuals (48).

\section{SECRETED PROTEIN ACIDIC AND RICH IN CYSTEINE}

SPARC belongs to a family of matricellular proteins that modulate cell interaction with the extracellular environment. There are currently six known members of the SPARC family. These members, along with some key features of them, are shown 
in Table 3. While their structures and functions are not identical, each member of the family possesses shared motifs and is secreted into the extracellular space where they influence the structure of the extracellular matrix and modulate various signaling pathways (58) such as the TGF- $\beta$ pathway $(30,58)$. Two particular members of this family, SPARC and Hevin/SPARCL1, are notable in that they have collagen binding domains in addition to the calcium binding domains exhibited by all of the other members of the protein family (30). The SPARCcollagen binding interaction is depicted in Figure 1. Nullification of SPARC expression decreases the expression of the proinflammatory cytokines IL-6, IP-10, and FAS/CD95 in rats (59). Hevin is a member of the SPARC protein family, which is most commonly expressed in the brain along with SPARC (30). Studies have found that SPARC has an antiadhesive effect on brain endothelial cells and decreases cerebral endothelial transepithelial/transendothelial electrical resistance (TEER), indicating decreased BBB integrity (60).

\section{SPARC expression in AD}

Within the brain, SPARC and Hevin are attributed to a variety of functions, such as the regulation of synaptogenesis and tissue remodeling following an injury. The proteins are primarily expressed in immune cells. While both SPARC and Hevin are produced by microglia (7) and astrocytes (61), Hevin is produced only by some neurons (62). Postmortem examination of the brains of AD and control individuals found that there is a notable upregulation of SPARC and downregulation of Hevin in the AD brains. As indicated in Figure 2, SPARC is expressed by microglia found in close proximity to pathological $A \beta$ amyloid plaques (7). Interestingly, while it seems that SPARC has a destructive effect on the BBB, which would exacerbate the $\mathrm{AD}$ condition, it appears to support the $\mathrm{A} \beta$ amyloid clearance process, which should have the opposite effect $(7,60)$. Hevin's role in BBB health is unclear, though it may be responsible for the initiation of the repair process by microglia (7).

\section{TABLE 3 Members of the SPARC protein family}

\begin{tabular}{|c|c|c|c|}
\hline $\begin{array}{l}\text { SPARC family } \\
\text { member }\end{array}$ & $\begin{array}{l}\text { Significant brain } \\
\text { expression }\end{array}$ & Binds to & Impact on cell adhesion \\
\hline SPARC & Yes $(7,30)$ & Collagen + calcium $(30)$ & Antiadhesion $(49,50)$ \\
\hline $\begin{array}{l}\text { Hevin/SPARC-like } 1 \\
\quad \text { (SPARCL1) }\end{array}$ & Yes $(7,30)$ & Collagen + calcium $(30)$ & Antiadhesion (51) \\
\hline Smoc-1 & Yes (52) & Calcium (30) & Unidentified \\
\hline Smoc-2 & No (53) & Calcium (30) & $\begin{array}{l}\text { No effect on non-epithelial } \\
\text { cells (53) }\end{array}$ \\
\hline Testicans/spocks & Yes $(54,55)$ & Calcium (30) & $\begin{array}{l}\text { Antiadhesion (testican-1) } \\
\text { (56) }\end{array}$ \\
\hline $\begin{array}{l}\text { Follastatin-like } 1 \\
\quad(\text { FSTL1) }\end{array}$ & Yes (57) & Calcium (30) & Unidentified \\
\hline
\end{tabular}

SARC, secreted protein acidic and rich in cysteine. 


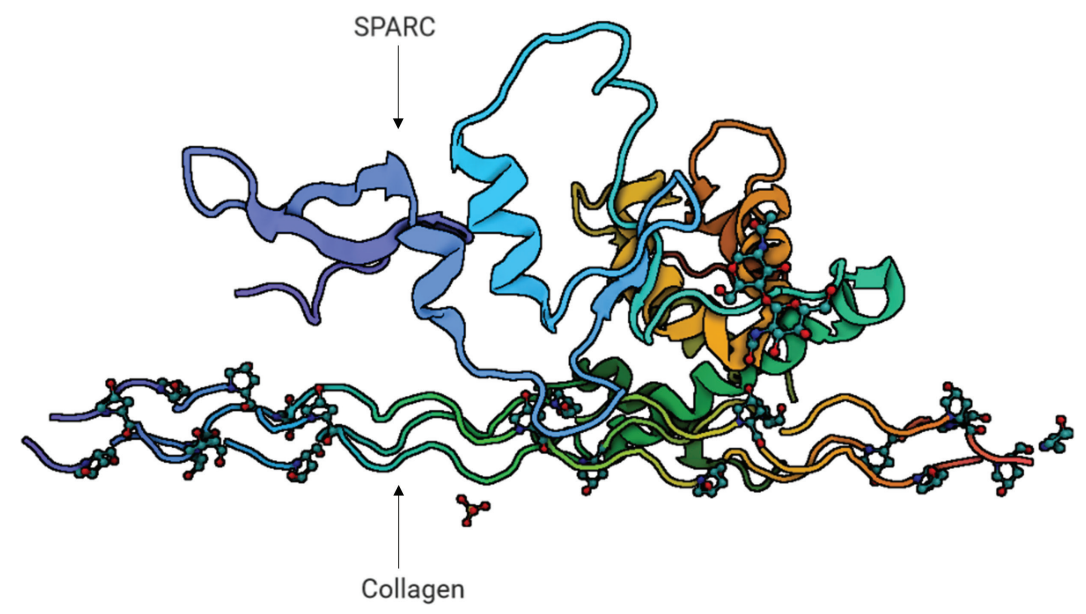

Figure 1. Secreted protein acidic and rich in cysteine (SPARC)-collagen binding. The bottom part of the structure diagram represents a collagen alpha-1(III) chain; the top part of the structure diagram represents SPARC. The SPARC-collagen binding site represents a potential target for agents that modify SPARC activity. Created with BioRender.com.

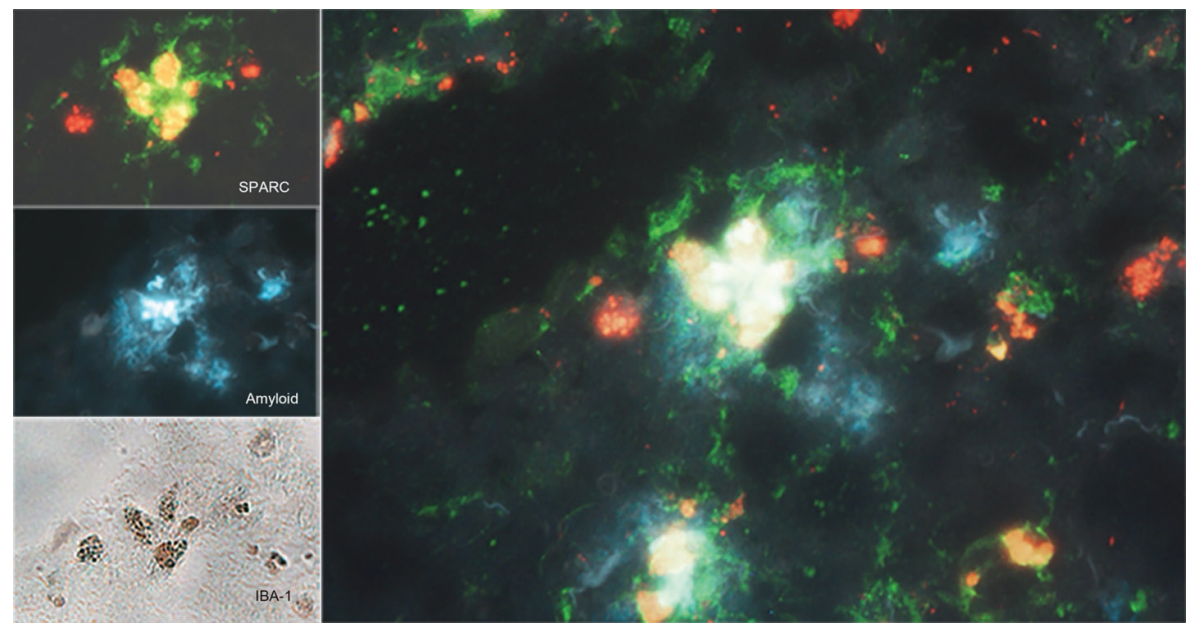

Figure 2. Secreted protein acidic and rich in cysteine (SPARC) is expressed by microglia found in close proximity to pathological Alzheimer's A $\beta$ amyloid aggregates. Analysis of cortical tissue from Alzheimer's disease patients reveals the presence of SPARC (in green) in and around glial cells within $A \beta$ amyloid (ThioS in blue) plaques. These SPARC-associated glial cells were identified as microglia (IBA-1 in HRP brown). Adapted from (7) under CC BY-NC 4.0 (https://creativecommons.org/licenses/by-nc/4.0/) license. Reproduced with permission.

\section{SPARC and the BBB}

Expression of SPARC is also associated with inflammatory responses. When testing the effects of various cytokines on SPARC expression and BBB permeability in hCMEC/D3 cell culture, it was found that TNF- $\alpha$ caused an upregulation in SPARC only in the absence of IFN- $\gamma$ that negated the effects of TNF- $\alpha$ (63). 
In the brain, SPARC is typically localized to astrocytic end-feet and cerebral endothelium. SPARC was experimentally determined to increase transendothelial permeability and affect the differentiation of endothelial cells through protein tyrosine kinase signaling (63). A particular area of interest is the SPARC-collagen binding domain. Increased levels of collagen IV, as well as general thickening, in the basement membrane of brain microvessels are noted in cases of AD (64); increases in SPARC show a corresponding increase in the levels of collagen $(65,66)$, and SPARC acts as a chaperone for collagen IV (67). Furthermore, abnormalities in the vasculature that surround the $A \beta$ amyloid plaques are associated with aberrant levels of collagen IV (68). The interactions between SPARC and collagen have been linked to inflammation and pathological fibrosis (69), as well as induction of a pro-inflammatory response in brain monocytes (64). The differential effects of SPARC may mean it can serve as an effective broad-spectrum therapeutic target.

\section{Rationale for SPARC protein as a potential Alzheimer's therapeutic target}

Although a better understanding of the disease and its mechanisms have provided avenues for druggable targets, attempts to develop effective ways to treat or reverse $\mathrm{AD}$ progression have been met with failure thus far. Perhaps targeting AD from multiple treatment angles may be the key. As vascular dysfunction is a substantial component of $\mathrm{AD}$, SPARC and other members of the protein family may be druggable targets for AD (70). Information on SPARC modifiers on the central nervous system is limited; however, such modifiers have been studied to a degree in the context of cancers $(71,72)$. Currently, the translational aspects of these drugs for AD are largely speculative. The SPARC-collagen binding site represents a reasonable start to the search, given the detailed research surrounding the structure and mechanism of the SPARC-collagen binding domain and knowledge of collagen binding with other molecules (73). A general diagram of how SPARC and Hevin, in particular, interact with the BBB is shown in Figure 3.

\section{FUTURE DIRECTIONS}

Research on the SPARC protein and molecules that can modify its activity is limited. Given that the process of drug discovery is capital-intensive and time-consuming, it may be prudent to establish what molecules modify the activity of SPARC and its relative such as Hevin. High-throughput screening has been applied to other molecules, in which batteries of mini-scale experiments assaying the activity of the target when introduced to a library of molecules are conducted (74). However, conducting this procedure on a compound library that can contain hundreds of thousands of molecules, with a generally low hit rate of modifying compounds, is costly; samples of every compound must first be synthesized before it can be tested. The use of screening tools that conduct the filtering of molecules in silico has become increasingly popular, as large numbers of molecules can be processed quickly and cheaply, so long as one has access to sufficient computational power (75). Molecules must be first tested both in vitro and in vivo and, ultimately, in humans before a drug 


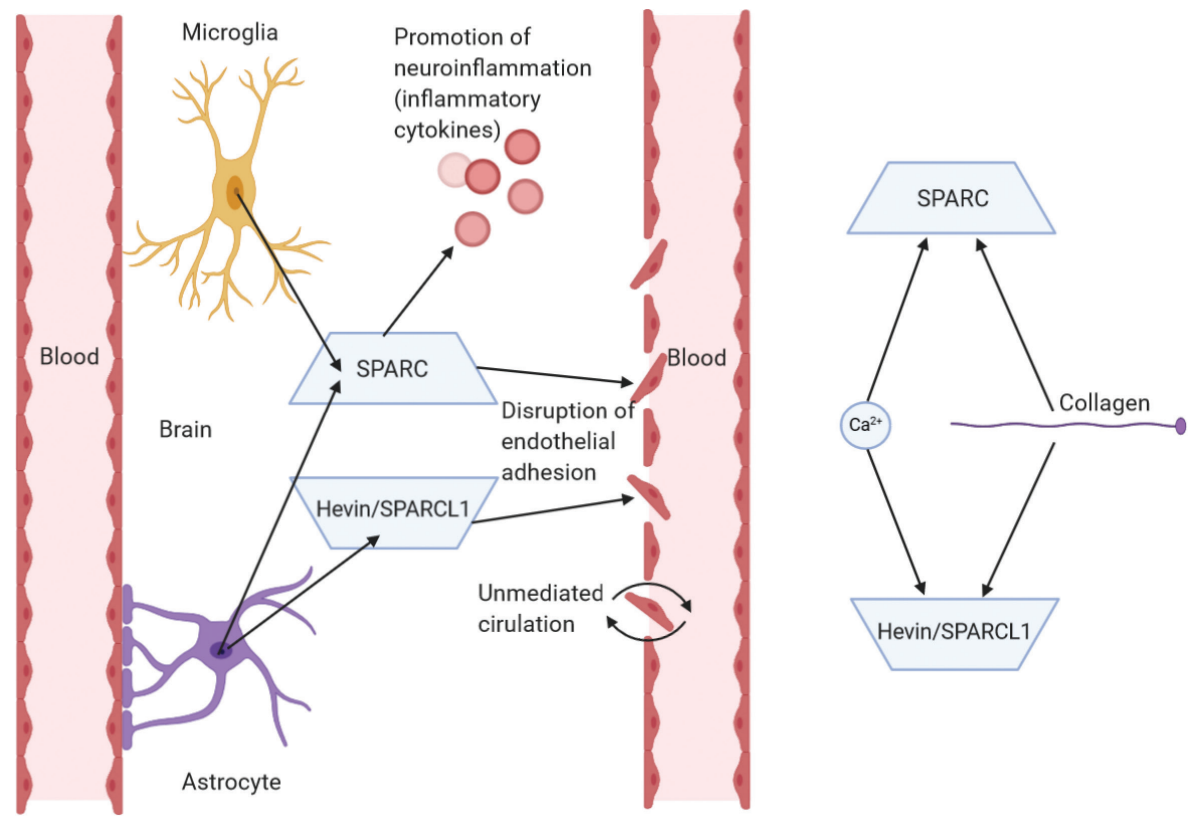

Figure 3. Secreted protein acidic and rich in cysteine (SPARC) and Hevin interactions with the blood-brain barrier (BBB). SPARC is produced primarily by microglia and astrocytes, while Hevin is primarily produced by astrocytes. SPARC and Hevin exert antiadhesive effects, and SPARC promotes the release of inflammatory cytokines in certain conditions. Both SPARC and Hevin are distinct from the other members of the SPARC protein family because they bind to collagen as well as calcium; both binding sites represent potential targets for Alzheimer's disease-modifying agents. Created with BioRender.com.

can be considered successful. The fast in silico screening compound hits can significantly reduce the time and costs of drug development (76).

We thus propose that such methods be used to identify inhibitors for SPARCcollagen binding. A variety of machine learning (ML) algorithms have been applied to the problem of drug discovery and molecular screening with considerable success; decision trees, support vector machines, and other classifiers have been applied to either structural or ligand-based virtual screening (VS) (77-79). Ligand-based approaches take the similarities of different molecules to other compounds that are known to be active against a target protein. Information on the molecules is generally taken from compound databases, which are filtered based on certain properties, such as those that influence pharmacokinetics and toxicity, in order to make the problem of screening a large number of molecules more computationally feasible (76). As the name implies, structure-based VS involves structural information, either obtained from techniques such as X-ray crystallography or, more commonly, data obtained from computational models. The molecular structures of the protein target and those of the structural databases are examined, in order to determine which will interact in the desired manner (76). Structural methods also encompass the development of novel molecules, 
as generative models, which are notable for their ability to use information gleaned from training data for the purpose of classification or prediction and create novel data for a novel sample of the given type.

Deep learning (DL), which involves ML algorithms that feature multiple neural network (NN) layers, has become prevalent in a variety of fields. NNs form the primary basic structure of DL models. Notable examples of NN-based drug discovery platforms include "AtomNet," developed by Wallach et al., a structurebased virtual screener based on a convolutional neural network (CNN) algorithm. Though typically applied to image processing and linguistic applications, a CNN model, which features layers of feature-reduction (convolution) and pooling operations, was trained on a set of molecular structures and tested against a set of benchmark decoy-structures. Performance of the CNN was found to be better than other ML methods (80). Thus, it may be the case that more research into some unorthodox NN strategies may provide a helpful performance boost for VS tools; such a tool could be useful in VS against SPARC protein target for AD drug discovery, as the limited data on SPARC target make in silico methods a practical predecessor to future in vitro and in vivo work and beyond.

\section{CONCLUSION}

Current evidence shows that the BBB plays a crucial role in a variety of neurological disorders, and its disruption is evident in $\mathrm{AD}$. There is a great deal of interplay between the various known hallmarks of $\mathrm{AD}$, such as the buildup of amyloid plaques, NFTs, and BBB degradation. Many risk factors tie into multiple facets of the disorder; $\mathrm{APOE} 4$, the most significant genetic risk factor for $\mathrm{AD}$ discovered to date, diminishes $A \beta$ clearance and inhibits BBB repair. TBI/mTBI and neuroinflammation contribute to AD pathogenesis and BBB damage. Gradual erosion of the $\mathrm{BBB}$ is a common part of the aging process, increasing an individual's vulnerabilities to further breakdown and neurodegenerative diseases. Given the importance of the health and stability of the $\mathrm{BBB}$, and the wide array of factors that can be detrimental to it, such as SPARC, more research into its mechanics, maintenance, and recovery pathways may be vital to understanding $\mathrm{AD}$ and how to treat it. DL-based VS tools may be employed to identify inhibitors of SPARCcollagen binding for AD drug discovery.

Acknowledgments: This work was partially supported by a grant from NIH National Institute on Aging (R01AG056614 to XH).

Conflict of Interest: The authors declare no potential conflicts of interest with respect to research, authorship, or publication of this chapter.

Copyright and Permission Statement: We confirm that the materials included in this chapter do not violate copyright laws. Where relevant, appropriate permissions have been obtained from the original copyright holder(s). All original sources have been appropriately acknowledged and referenced. 


\section{REFERENCES}

1. Alzheimer's-Association. 2019 Alzheimer's disease facts and figures. Alzheimers Dement. 2019;15(3):321-87. http://dx.doi.org/10.1016/j.jalz.2019.01.010

2. El-Hayek YH, Wiley RE, Khoury CP, Daya RP, Ballard C, Evans AR, et al. Tip of the iceberg: Assessing the global socioeconomic costs of Alzheimer's disease and related dementias and strategic implications for stakeholders. J Alzheimers Dis. 2019;70(2):323-41. http://dx.doi.org/10.3233/JAD-190426

3. Mehta D, Jackson R, Paul G, Shi J, Sabbagh M. Why do trials for Alzheimer's disease drugs keep failing? A discontinued drug perspective for 2010-2015. Expert Opin Investig Drugs. 2017;26(6):735-9. http://dx.doi.org/10.1080/13543784.2017.1323868

4. Liebner S, Dijkhuizen RM, Reiss Y, Plate KH, Agalliu D, Constantin G. Functional morphology of the blood-brain barrier in health and disease. Acta Neuropathol. 2018;135(3):311-36. http://dx.doi. org/10.1007/s00401-018-1815-1

5. Yamazaki Y, Kanekiyo T. Blood-brain barrier dysfunction and the pathogenesis of Alzheimer's disease. Int J Mol Sci. 2017;18(9):1965. http://dx.doi.org/10.3390/ijms18091965

6. Kong W, Mou X, Liu Q, Chen Z, Vanderburg CR, Rogers JT, et al. Independent component analysis of Alzheimer's DNA microarray gene expression data. Mol Neurodegen. 2009;4(1):5. http://dx.doi. org/10.1186/1750-1326-4-5

7. Strunz M, Jarrell JT, Cohen DS, Rosin ER, Vanderburg CR, Huang X. Modulation of SPARC/hevin proteins in Alzheimer's disease brain injury. J Alzheimers Dis. 2019;68(2):695-710. http://dx.doi.org/ 10.3233/JAD-181032

8. Amemori T, Jendelova P, Ruzicka J, Urdzikova LM, Sykova E. Alzheimer's disease: Mechanism and approach to cell therapy. Int J Mol Sci. 2015;16(11):26417-51. http://dx.doi.org/10.3390/ ijms161125961

9. Erdo F, Denes L, de Lange E. Age-associated physiological and pathological changes at the bloodbrain barrier: A review. J Cereb Blood Flow Metab. 2017;37(1):4-24. http://dx.doi.org/10.1177 10271678X16679420

10. Montagne A, Barnes SR, Sweeney MD, Halliday MR, Sagare AP, Zhao Z, et al. Blood-brain barrier breakdown in the aging human hippocampus. Neuron. 2015;85(2):296-302. http://dx.doi.org/ 10.1016/j.neuron.2014.12.032

11. Erickson MA, Banks WA. Age-associated changes in the immune system and blood(-)brain barrier functions. Int J Mol Sci. 2019;20(7):1632. http://dx.doi.org/10.3390/ijms20071632

12. Mooradian AD. Potential mechanisms of the age-related changes in the blood-brain barrier. Neurobiol Aging. 1994;15(6):751-5; discussion 61-2, 67. http://dx.doi.org/10.1016/0197-4580(94)90058-2

13. Young VG, Halliday GM, Kril JJ. Neuropathologic correlates of white matter hyperintensities. Neurology. 2008;71(11):804-11. http://dx.doi.org/10.1212/01.wnl.0000319691.50117.54

14. Brown WR, Moody DM, Thore CR, Challa VR, Anstrom JA. Vascular dementia in leukoaraiosis may be a consequence of capillary loss not only in the lesions, but in normal-appearing white matter and cortex as well. J Neurol Sci. 2007;257(1-2):62-6. http://dx.doi.org/10.1016/j.jns.2007.01.015

15. Oparil S, Acelajado MC, Bakris GL, Berlowitz DR, Cifkova R, Dominiczak AF, et al. Hypertension. Nat Rev Dis Primers. 2018;4:18014. http://dx.doi.org/10.1038/nrdp.2018.14

16. Zeevi N, Pachter J, McCullough LD, Wolfson L, Kuchel GA. The blood-brain barrier: Geriatric relevance of a critical brain-body interface. J Am Geriatr Soc. 2010;58(9):1749-57. http://dx.doi. org/10.1111/j.1532-5415.2010.03011.x

17. Louveau A, Harris TH, Kipnis J. Revisiting the mechanisms of CNS immune privilege. Trends Immunol. 2015;36(10):569-77. http://dx.doi.org/10.1016/j.it.2015.08.006

18. Montagne A, Zhao Z, Zlokovic BV. Alzheimer's disease: A matter of blood-brain barrier dysfunction? J Exp Med. 2017;214(11):3151-69. http://dx.doi.org/10.1084/jem.20171406

19. Matcovitch-Natan O, Winter DR, Giladi A, Aguilar SV, Spinrad A, Sarrazin S, et al. Microglia development follows a stepwise program to regulate brain homeostasis. Science. 2016;353(6301):aad8670. http:// dx.doi.org/10.1126/science.aad8670

20. Lenz KM, Nelson LH. Microglia and beyond: Innate immune cells as regulators of brain development and behavioral function. Front Immunol. 2018;9:698. http://dx.doi.org/10.3389/fimmu.2018.00698 
21. Condello C, Yuan P, Schain A, Grutzendler J. Microglia constitute a barrier that prevents neurotoxic protofibrillar Abeta42 hotspots around plaques. Nat Commun. 2015;6:6176. http://dx.doi. org/10.1038/ncomms 7176

22. da Fonseca AC, Matias D, Garcia C, Amaral R, Geraldo LH, Freitas C, et al. The impact of microglial activation on blood-brain barrier in brain diseases. Front Cell Neurosci. 2014;8:362. http://dx.doi. org/10.3389/fncel.2014.00362

23. Spangenberg EE, Green KN. Inflammation in Alzheimer's disease: Lessons learned from microgliadepletion models. Brain Behav Immun. 2017;61:1-11. http://dx.doi.org/10.1016/j.bbi.2016.07.003

24. Verkhratsky A, Nedergaard M. Physiology of astroglia. Physiol Rev. 2018;98(1):239-389. http:// dx.doi.org/10.1152/physrev.00042.2016

25. Chapouly C, Tadesse Argaw A, Horng S, Castro K, Zhang J, Asp L, et al. Astrocytic TYMP and VEGFA drive blood-brain barrier opening in inflammatory central nervous system lesions. Brain. 2015;138(Pt 6):1548-67. http://dx.doi.org/10.1093/brain/awv077

26. Sawikr Y, Yarla NS, Peluso I, Kamal MA, Aliev G, Bishayee A. Neuroinflammation in Alzheimer's disease: The preventive and therapeutic potential of polyphenolic nutraceuticals. Adv Protein Chem Struct Biol. 2017;108:33-57. http://dx.doi.org/10.1016/bs.apcsb.2017.02.001

27. Heneka MT, Carson MJ, El Khoury J, Landreth GE, Brosseron F, Feinstein DL, et al. Neuroinflammation in Alzheimer's disease. Lancet Neurol. 2015;14(4):388-405. http://dx.doi.org/10.1016/S14744422(15)70016-5

28. Hurtado-Alvarado G, Dominguez-Salazar E, Pavon L, Velazquez-Moctezuma J, Gomez-Gonzalez B. Blood-brain barrier disruption induced by chronic sleep loss: Low-grade inflammation may be the link. J Immunol Res. 2016;2016:4576012. http://dx.doi.org/10.1155/2016/4576012

29. Mattson MP, Arumugam TV. Hallmarks of brain aging: Adaptive and pathological modification by metabolic states. Cell Metab. 2018;27(6):1176-99. http://dx.doi.org/10.1016/j.cmet.2018.05.011

30. Bradshaw AD. Diverse biological functions of the SPARC family of proteins. Int J Biochem Cell Biol. 2012;44(3):480-8. http://dx.doi.org/10.1016/j.biocel.2011.12.021

31. Gardner RC, Yaffe K. Epidemiology of mild traumatic brain injury and neurodegenerative disease. Mol Cell Neurosci. 2015;66(Pt B):75-80. http://dx.doi.org/10.1016/j.mcn.2015.03.001

32. Szarka N, Toth L, Czigler A, Kellermayer Z, Ungvari Z, Amrein K, et al. Single mild traumatic brain injury induces persistent disruption of the blood-brain barrier, neuroinflammation and cognitive decline in hypertensive rats. Int J Mol Sci. 2019;20(13):3223. http://dx.doi.org/10.3390/ ijms20133223

33. Fehily B, Fitzgerald M. Repeated mild traumatic brain injury: Potential mechanisms of damage. Cell Transplant. 2017;26(7):1131-55. http://dx.doi.org/10.1177/0963689717714092

34. Laurer HL, Bareyre FM, Lee VM, Trojanowski JQ, Longhi L, Hoover R, et al. Mild head injury increasing the brain's vulnerability to a second concussive impact. J Neurosurg. 2001;95(5):859-70. http://dx.doi.org/10.3171/jns.2001.95.5.0859

35. Salehi A, Zhang JH, Obenaus A. Response of the cerebral vasculature following traumatic brain injury. J Cereb Blood Flow Metab. 2017;37(7):2320-39. http://dx.doi.org/10.1177/0271678X17701460

36. Perry DC, Sturm VE, Peterson MJ, Pieper CF, Bullock T, Boeve BF, et al. Association of traumatic brain injury with subsequent neurological and psychiatric disease: A meta-analysis. J Neurosurg. 2016;124(2):511-26. http://dx.doi.org/10.3171/2015.2.JNS14503

37. Tremblay S, Desjardins M, Bermudez P, Iturria-Medina Y, Evans AC, Jolicoeur P, et al. Mild traumatic brain injury: The effect of age at trauma onset on brain structure integrity. Neuroimage Clin. 2019;23:101907. http://dx.doi.org/10.1016/j.nicl.2019.101907

38. Nation DA, Sweeney MD, Montagne A, Sagare AP, D'Orazio LM, Pachicano M, et al. Blood-brain barrier breakdown is an early biomarker of human cognitive dysfunction. Nat Med. 2019;25(2): 270-6. http://dx.doi.org/10.1038/s41591-018-0297-y

39. Apostolova LG, Risacher SL, Duran T, Stage EC, Goukasian N, West JD, et al. Associations of the top 20 Alzheimer disease risk variants with brain amyloidosis. JAMA Neurol. 2018;75(3):328-41. http:// dx.doi.org/10.1001/jamaneurol.2017.4198

40. Li J, Luo J, Liu L, Fu H, Tang L. The genetic association between apolipoprotein E gene polymorphism and Parkinson disease: A meta-analysis of 47 studies. Medicine (Baltimore). 2018;97(43):el2884. http://dx.doi.org/10.1097/MD.0000000000012884 
41. Agosta F, Vossel KA, Miller BL, Migliaccio R, Bonasera SJ, Filippi M, et al. Apolipoprotein E epsilon4 is associated with disease-specific effects on brain atrophy in Alzheimer's disease and frontotemporal dementia. Proc Natl Acad Sci U S A. 2009;106(6):2018-22. http://dx.doi.org/10.1073/pnas.0812697106

42. Ji Y, Liu M, Huo YR, Liu S, Shi Z, Liu S, et al. Apolipoprotein E $\varepsilon 4$ frequency is increased among Chinese patients with frontotemporal dementia and Alzheimer's disease. Dement Geriatr Cogn Disord. 2013;36(3-4):163-70. http://dx.doi.org/10.1159/000350872

43. Slooter AJ, Cruts M, Kalmijn S, Hofman A, Breteler MM, Van Broeckhoven C, et al. Risk estimates of dementia by apolipoprotein E genotypes from a population-based incidence study: The Rotterdam Study. Arch Neurol. 1998;55(7):964-8. http://dx.doi.org/10.1001/archneur.55.7.964

44. Liu CC, Liu CC, Kanekiyo T, Xu H, Bu G. Apolipoprotein E and Alzheimer disease: Risk, mechanisms and therapy. Nat Rev Neurol. 2013;9(2):106-18. http://dx.doi.org/10.1038/nrneurol.2012.263

45. Salloway S, Gur T, Berzin T, Tavares R, Zipser B, Correia S, et al. Effect of APOE genotype on microvascular basement membrane in Alzheimer's disease. J Neurol Sci. 2002;203-204:183-7. http:// dx.doi.org/10.1016/S0022-510X(02)00288-5

46. Zipser BD, Johanson CE, Gonzalez L, Berzin TM, Tavares R, Hulette CM, et al. Microvascular injury and blood-brain barrier leakage in Alzheimer's disease. Neurobiol Aging. 2007;28(7):977-86. http:// dx.doi.org/10.1016/j.neurobiolaging.2006.05.016

47. Main BS, Villapol S, Sloley SS, Barton DJ, Parsadanian M, Agbaegbu C, et al. Apolipoprotein E4 impairs spontaneous blood brain barrier repair following traumatic brain injury. Mol Neurodegener. 2018;13(1):17. http://dx.doi.org/10.1186/s13024-018-0249-5

48. Halliday MR, Rege SV, Ma Q, Zhao Z, Miller CA, Winkler EA, et al. Accelerated pericyte degeneration and blood-brain barrier breakdown in apolipoprotein E4 carriers with Alzheimer's disease. J Cereb Blood Flow Metab. 2016;36(1):216-27. http://dx.doi.org/10.1038/jcbfm.2015.44

49. Mayer U, Aumailley M, Mann K, Timpl R, Engel J. Calcium-dependent binding of basement membrane protein BM-40 (osteonectin, SPARC) to basement membrane collagen type IV. Eur J Biochem. 1991;198(1):141-50. http://dx.doi.org/10.1111/j.1432-1033.1991.tb15996.x

50. Rosenblatt S, Bassuk J, Alpers C, Sage E, Timpl R, Preissner K. Differential modulation of cell adhesion by interaction between adhesive and counter-adhesive proteins: Characterization of the binding of vitronectin to osteonectin (BM40, SPARC). Biochem J. 1997;324(Pt 1):311. http://dx.doi.org/10.1042/ bj3240311

51. Girard J-P, Springer TA. Modulation of endothelial cell adhesion by hevin, an acidic protein associated with high endothelial venules. J Biol Chem. 1996;271(8):4511-17. http://dx.doi.org/10.1074/jbc.271.8.4511

52. Gersdorff N, Müller M, Schall A, Miosge N. Secreted modular calcium-binding protein-1 localization during mouse embryogenesis. Histochem Cell Biol. 2006;126(6):705-12. http://dx.doi.org/10.1007/ s00418-006-0200-7

53. Maier S, Paulsson M, Hartmann U. The widely expressed extracellular matrix protein SMOC-2 promotes keratinocyte attachment and migration. Exp Cell Res. 2008;314(13):2477-87. http:// dx.doi.org/10.1016/j.yexcr.2008.05.020

54. Vannahme C, Schübel S, Herud M, Gösling S, Hülsmann H, Paulsson M, et al. Molecular cloning of testican-2: Defining a novel calcium-binding proteoglycan family expressed in brain. J Neurochem. 1999;73(1):12-20. http://dx.doi.org/10.1046/j.1471-4159.1999.0730012.x

55. Charbonnier F, Chanoine C, Cifuentes-Diaz C, Gallien C, Rieger F, Alliel P, et al. Expression of the proteoglycan SPOCK during mouse embryo development. Mech Dev. 2000;90(2):317-21. http:// dx.doi.org/10.1016/S0925-4773(99)00255-5

56. Marr HS, Edgell C-JS. Testican-1 inhibits attachment of neuro-2a cells. Matrix Biol. 2003;22(3): 259-66. http://dx.doi.org/10.1016/S0945-053X(03)00036-2

57. Liu R, Yang Y, Shen J, Chen H, Zhang Q, Ba R, et al. Fstll is involved in the regulation of radial glial scaffold development. Mol Brain. 2015;8(1):1-14. http://dx.doi.org/10.1186/s13041-015-0144-8

58. Atorrasagasti C, Peixoto E, Aquino JB, Kippes N, Malvicini M, Alaniz L, et al. Lack of the matricellular protein SPARC (secreted protein, acidic and rich in cysteine) attenuates liver fibrogenesis in mice. PLoS One. 2013;8(2):e54962. http://dx.doi.org/10.1371/journal.pone.0054962

59. Mazzolini G, Atorrasagasti C, Onorato A, Peixoto E, Schlattjan M, Sowa J-P, et al. SPARC expression is associated with hepatic injury in rodents and humans with non-alcoholic fatty liver disease. Sci Rep. 2018;8(1):725. http://dx.doi.org/10.1038/s41598-017-18981-9 
60. Tilling $\mathrm{T}$, Korte D, Hoheisel D, Galla HJ. Basement membrane proteins influence brain capillary endothelial barrier function in vitro. J Neurochem. 1998;71(3):1151-7. http://dx.doi. org/10.1046/j.1471-4159.1998.71031151.x

61. Kucukdereli H, Allen NJ, Lee AT, Feng A, Ozlu MI, Conatser LM, et al. Control of excitatory CNS synaptogenesis by astrocyte-secreted proteins Hevin and SPARC. Proc Natl Acad Sci U S A. 2011;108(32):E440-9. http://dx.doi.org/10.1073/pnas.1104977108

62. Mongrédien R, Erdozain AM, Dumas S, Cutando L, Del Moral AN, Puighermanal E, et al. Cartography of hevin-expressing cells in the adult brain reveals prominent expression in astrocytes and parvalbumin neurons. Brain Structure and Function. 2019;224(3):1219-44. http://dx.doi. org/10.1007/s00429-019-01831-x

63. Alkabie S, Basivireddy J, Zhou L, Roskams J, Rieckmann P, Quandt JA. SPARC expression by cerebral microvascular endothelial cells in vitro and its influence on blood-brain barrier properties. J Neuroinflammation. 2016;13(1):225. http://dx.doi.org/10.1186/s12974-016-0657-9

64. Kalaria R. The blood-brain barrier and cerebrovascular pathology in Alzheimer's disease. Brain Res. 1999;814:164-70. http://dx.doi.org/10.1111/j.1749-6632.1999.tb07821.x

65. Zhou X, Tan FK, Guo X, Arnett FC. Attenuation of collagen production with small interfering RNA of SPARC in cultured fibroblasts from the skin of patients with scleroderma. Arthr Rheum. 2006;54(8):2626-31. http://dx.doi.org/10.1002/art.21973

66. McCurdy S, Baicu CF, Heymans S, Bradshaw AD. Cardiac extracellular matrix remodeling: Fibrillar collagens and Secreted Protein Acidic and Rich in Cysteine (SPARC). J Mol Cell Cardiol. 2010;48(3):544-9. http://dx.doi.org/10.1016/j.yjmcc.2009.06.018

67. Bradshaw AD. The role of SPARC in extracellular matrix assembly. J Cell Commun Signal. 2009; 3(3-4):239. http://dx.doi.org/10.1007/s12079-009-0062-6

68. Kawai M, Kalaria R, Harik S, Perry G. The relationship of amyloid plaques to cerebral capillaries in Alzheimer's disease. Am J Pathol. 1990;137(6):1435.

69. Wang J-C, Lai S, Guo X, Zhang X, De Crombrugghe B, Sonnylal S, et al. Attenuation of fibrosis in vitro and in vivo with SPARC siRNA. Arthr Res Ther. 2010;12(2):R60. http://dx.doi.org/10.1186/ar2973

70. Strickland S. Blood will out: Vascular contributions to Alzheimer's disease. J Clin Investig. 2018;128(2):556-63. http://dx.doi.org/10.1172/JC197509

71. Tai IT, Tang MJ. SPARC in cancer biology: Its role in cancer progression and potential for therapy. Drug Resist Updat. 2008;11(6):231-46. http://dx.doi.org/10.1016/j.drup.2008.08.005

72. VazJ, Ansari D, Sasor A, Andersson R. SPARC: A potential prognostic and therapeutic target in pancreatic cancer. Pancreas. 2015;44(7):1024-35. http://dx.doi.org/10.1097/MPA.0000000000000409

73. Eichenbaum H, Dudchenko P, Wood E, Shapiro M, Tanila H. The hippocampus, memory, and place cells: Is it spatial memory or a memory space? Neuron. 1999;23(2):209-26. http://dx.doi. org/10.1016/S0896-6273(00)80773-4

74. Carnero A. High throughput screening in drug discovery. Clin Transl Oncol. 2006;8(7):482-90. http://dx.doi.org/10.1007/s12094-006-0048-2

75. Carpenter K, Huang X. Is it a prime time for AI-powered virtual drug screening? EC Pharmacol Toxicol. 2017;SI(1):16-17.

76. Sliwoski G, Kothiwale S, Meiler J, Lowe EW, Jr. Computational methods in drug discovery. Pharmacol Rev. 2013;66(1):334-95. http://dx.doi.org/10.1124/pr.112.007336

77. Lavecchia A. Machine-learning approaches in drug discovery: Methods and applications. Drug Discov Today. 2015;20(3):318-31. http://dx.doi.org/10.1016/j.drudis.2014.10.012

78. Carpenter KA, Cohen DS, Jarrell JT, Huang X. Deep learning and virtual drug screening. Fut Med Chem. 2018;10(21):2557-67. http://dx.doi.org/10.4155/fmc-2018-0314

79. Carpenter KA, Huang X. Machine learning-based virtual screening and its applications to Alzheimer's drug discovery: A review. Curr Pharmaceut Design. 2018;24(28):3347-58. http://dx.doi.org/10.2174/ 1381612824666180607124038

80. Wallach I, Dzamba M, Heifets A. AtomNet: A deep convolutional neural network for bioactivity prediction in structure-based drug discovery. arXiv preprint arXiv:151002855. 2015. 
